\title{
O ENIGMA DA ESCRITURA: CLARICE LISPECTOR MESTRE OU REFÉM DE SUA ESCRITA?
}

\author{
Maria Elenice Costa Lima \\ Vera Lucia Albuquerque de Moraes
}

\begin{abstract}
RESUMO: O presente trabalho tem por objetivo suscitar a questão da autoria na obra da escritora brasileira Clarice Lispector, partindo, sobretudo, da leitura e análise das crônicas do livro A descoberta do mundo (1999) e das cartas publicadas em Cartas perto do coração (2001) que diz respeito às correspondências trocadas entre Clarice e Fernando Sabino. Para isso, serão discutidas, principalmente, as ideias de Roland Barthes que tratam da morte do autor e as de Michel Foucault acerca da função autor.
\end{abstract}

PALAVRAS-CHAVE: Autoria, Clarice, escritura.

ABSTRACT: The present research aims to rouse the authorship matter in the work of the Brazilian writer Clarice Lispector, starting, mainly, from the reading and analysis of the book A descoberta do mundo (1999) chronicles and the letters published in Cartas perto do coração (2001) which regard the writings exchanged between Clarice and Fernando Sabino. For all this, it will be discussed, mainly, the ideas of Roland Barthes that deal with the death of the author and the ones of Michel Foucault about the author function.

KEY WORDS: Authorship, Clarice, writer.

ESCREVER

Não se $f a z$ uma frase. A frase nasce.

(Clarice Lispector)

Ao pensar a figura do autor, inúmeras questões são suscitadas. Entre elas as mais fáceis, talvez, de serem apontadas sejam: quem é ou quem foi essa figura? Como se portou diante do mundo, dos outros e de si mesmo? Quais fatos extraordinários vivenciou? Entre outras. Essas indagações são fruto, na maioria das vezes, da curiosidade e, até mesmo, da vontade de dar ao autor um ar de superiodade, misticismo e, quiçá, ficcionalidade. Elas vêm da impossibilidade primeira de muitos leitores e estudiosos de considerar ele, o autor, um ser humano normal. É isso que vem ao longo dos anos acontecendo com a escritora brasileira Clarice Lispector. Várias têm sido as especulações em torno de sua vida pessoal, a fim de demonstrar acontecimentos extraordinários que a tornam, sobretudo, uma marca mercadológica. 
É mister admitir que Clarice realmente tem vários quesitos para ser vista como um Ser exótico, entre eles: o fato de ter sido gerada na expectativa de restabelecer a saúde de sua genitora; ter chegado ao Brasil na companhia dos pais quando ainda era bebê; perder a mãe durante a infância, frustrando assim a crença judaica de que o nascimento de uma criança é capaz de curar a mulher de qualquer enfermidade; formar-se em Direito, sem nunca ter se interessado em buscar o diploma; lançar seu primeiro livro Perto do coração selvagem (1943) no auge da juventude; casar-se com o diplomata Maury Gurgel Valente, a quem teve que acompanhar para a Europa em plena Segunda Guerra Mundial e de ter se apaixonado pelo escritor Lúcio Cardoso sem a possibilidade de ser correspondida devido a opção sexual dele. Contudo, vale ressaltar que a maneira peculiar e íntima com que a escritora tece seu texto, utilizando elementos até então pouco explorados como o monólogo interior, o fluxo da consciência, a epifania e a desautomatização da escrita tão presentes nos seus contos e romances, é mais exótica do que qualquer coisa relacionada à sua vida pessoal.

Por isso, pode-se afirmar que a escrita de Clarice Lispector, com seu caráter inovador e até mesmo transgressor, sintetiza em si mesma a ascensão das escritoras femininas brasileiras a patamares internacionais, pois imprime em sua literatura elementos que até então só haviam sido encontrados num James Joyce ou numa Virgínia Wolf. É isso que possibilita à ficção clariciana apresentar sua própria realidade, a partir de uma linguagem marcante, diferente, 'coisificada' que se comunica metaforicamente com o mundo, como nos alerta Antonio Candido:

\footnotetext{
Por outras palavras, Clarice mostrava que a realidade social ou pessoal (que fornece o tema), e o instrumento verbal (que institui a linguagem) se justificam antes de mais nada pelo fato de produzirem uma realidade própria, com sua inteligibilidade específica. Não se trata mais de ver o texto como algo que se esgota ao conduzir a este ou àquele aspecto do mundo e do ser; mas de lhe pedir que crie para nós o mundo, ou um mundo que existe e atua na medida em que é discurso literário. (CANDIDO, 2006, p. 250)
}

A fim de melhor discutir essas ideias, o presente trabalho optou por abordar algumas crônicas do livro A descoberta do mundo (1999) e cartas trocadas entre a escritora e o seu amigo, também escritor, Fernando Sabino, copiladas em Cartas perto do coração (2001). A escolha do primeiro livro se deve, principalmente, ao fato de que embora seus textos tenham sido apresentados como crônicas, se observados detidamente em seu conjunto, verifica-se que este contém peças e fragmentos de características bem diversificadas, tais como: contos 
extraídos de outros livros, trechos de cartas, anotações, novelas, recortes memorialistas, diálogos, fragmentos de entrevistas, opiniões sobre a literatura, o fazer literário, a importância da leitura e dos livros, entre outros assuntos - todo esse material contemplando sensíveis observações sobre os estágios da existência humana. Quanto a escolha do segundo é devida a intimidade com que os escritores compartilham suas impressões e aflições sobre o processo de escritura, apontando os caminhos trilhados pelo livro que ainda está por vir. Nas correspondências trocadas entre Clarice e Fernando há o tracejado da escritura clariciana em seu processo de composição.

Nascida na Ucrânia oficialmente, segundo a pesquisadora Nádia Batella Gotlib (2009), em 10 de dezembro de 1920, Lispector tem origens russas, ucranianas e judaicas, além de considerar-se brasileira de nascimento, apesar de não o ser. Isso fica explícito, quando em carta, datada de 3 de junho de 1942, se reporta ao presidente Getúlio Vargas para pedir que este despache seu pedido de naturalização. Nesta, fica evidente a íntima ligação da escritora com o Brasil, ocasionada, principalmente, pelo uso dos elementos primordiais de uma nação: a fala e a escrita, conforme se pode perceber:

Senhor Presidente Getúlio Vargas:

Quem lhe escreve é uma jornalista, ex-redatora da Agência Nacional (Departamento de Agência e Propaganda), atualmente n'A noite, acadêmica da Faculdade de Direito e, casualmente, russa também.

Uma russa de 21 anos de idade e que está no Brasil há 21 anos menos alguns meses. Que não conhece uma só palavra de russo mas que pensa, fala, escreve e age em português, fazendo disso sua profissão e nisso pousando todos os projetos do seu futuro próximo e longínquo. Que não tem pai nem mãe - o primeiro assim como as irmãs da signatária, brasileiro naturalizado - e que por isso não se sente de modo algum presa ao país de onde veio, nem sequer por ouvir relatos sobre ele. Que deseja casar-se com brasileiro e ter filhos brasileiros. Que, se fosse obrigada a voltar à Rússia, lá se sentiria irremediavelmente estrangeira, sem amigos, sem profissão, sem esperanças.

Senhor Presidente. Não pretendo afirmar que tenho prestado grandes serviços à Nação - requisito que poderia alegar para ter direito de pedir a V. Ex. ${ }^{a}$ a dispensa de um ano de prazo, necessário a minha naturalização. Sou jovem e, salvo em ato de heroísmo, não poderia ter servido ao Brasil senão fragilmente. Demonstrei minha ligação com esta terra e meu desejo de servi-la, cooperando com o DIP, por meio de reportagens e artigos, distribuídos aos jornais do Rio e dos estados, na divulgação e na propaganda do governo de V. Ex. ${ }^{a}$. E, de um modo geral, trabalhando na imprensa diária, o grande elemento de aproximação entre governo e povo.

Como jornalista tomei parte em comemorações das grandes datas nacionais, participei da inauguração de inúmeras obras iniciadas por V. Ex. ${ }^{a}$, e estive 
mesmo ao lado de V. Ex. ${ }^{a}$ mais de uma vez, sendo que a última em $1^{\circ}$ de maio de 1941, Dia do Trabalho.

Se trago a V. Ex. ${ }^{a}$ o resumo dos meus trabalhos jornalísticos não é para pedir-lhe, como recompensa, o direito de ser brasileira. Prestei esses serviços espontânea e naturalmente, e nem poderia deixar de executá-los. Se neles falo é para atestar que já sou brasileira.

Posso apresentar provas materiais de tudo o que afirmo. Infelizmente, o que não posso provar materialmente - e que, no entanto, é o que mais importa é que tudo que fiz tinha como núcleo minha real união com o país e que não possuo, nem elegeria, outra pátria senão o Brasil.

Senhor Presidente. Tomo a liberdade de solicitar a V. Ex. ${ }^{a}$ a dispensa do prazo de um ano, que se deve seguir ao processo que atualmente transita pelo Ministério da Justiça, com todos os requisitos satisfeitos. Poderei trabalhar, formar-me, fazer os indispensáveis projetos para o futuro, com segurança e estabilidade. A assinatura de V. Ex. ${ }^{a}$ tornará de direito uma situação de fato. Creia-me, Senhor Presidente, ela alargará minha vida. E um dia saberei provar que não a usei inutilmente.

Clarice Lispector.

(LISPECTOR, 2002, p. 34-35 - grifo nosso)

As partes em negrito comprovam que a jovem Clarice não apenas se afirmava como brasileira, mas que ela se sentia e era brasileira de fato. Afinal, fora no Brasil, utilizando o português brasileiro, que aprendera a pensar, falar, escrever e agir. Contudo, não se pode esquecer as fortes influências estrangeiras arraigadas em sua vida e muito menos deixar-se de considerar a possibilidade de que talvez esteja aí os motivos de uma procura constante do outro em sua escrita. Essa busca percorre toda a sua obra, desde os romances, os contos, as crônicas e as correspondências até os textos que eram publicados nos jornais sob os pseudônimos de Teresa Quadros e Helen Palmer. Assim, é possível flagrar em seus escritos a versatilidade que forma o outro. Um outro que surge do acaso, como o cego mascando chicles do conto "Amor" e o mendigo com a ferida na perna de "A Bela e a Fera ou A Ferida Grande Demais", ou mesmo da fragilidade das relações afetivas, como mãe e filha de "Laços de Família”. Um outro que nasce das sutilezas do cotidiano, da presença de uma ausência, como diria Drummond. Sobre o outro na obra de Clarice, Regina Pontieri considera:

Clarice tematiza em sua Obra muitas das formas que o outro - como inferior e excluído - tem tomado em nossa cultura. A mulher, o animal, o pobre, o louco, o primitivo, o intuitivo. Essa legião de avatares do outro parece servir para evidenciar (...) a busca sistemática de apagamento de fronteiras entre os pólos, apagamento que não os anula mas os faz coexistir. Reconstrói-se a alteridade não como aquilo que se exclui ou recalca mas, ao contrário, como condição de possibilidade de construção de um eu que seja o avesso do outro. (PONTIERI, 1999, p. 28-29) 
E é nessa constante busca pelo outro que está o ponto crucial da autoria na obra de Lispector e na qual se pode vislumbrar até que ponto ela se torna mestre ou refém de sua escritura, pois é através da descrição dos sentimentos, pensamentos e até mesmo ações de suas personagens que a escritora demonstra as idiossincrasias que revestem o seu eu. É no outro que ela se afirma e se reconhece enquanto Ser. É o outro enquanto leitor comum ou crítico literário que assegura seu "status" de escritora, uma vez que é a tríade autor, obra e leitor, tão bem analisada pelo sociólogo e crítico Antonio Candido (1981), que compõe o sistema literário.

Tendo por base essa contínua relação com o outro inerente aos textos de Clarice é interessante observar o "recado" que ela manda ao responsável pelas correções de seu texto no jornal:

\section{AO LINOTIPISTA}

Desculpe eu estar errando tanto na máquina. Primeiro é porque minha mão direita foi queimada. Segundo, não sei por quê.

Agora um pedido: não me corrija. A pontuação é a respiração da frase, e minha frase respira assim. E se você me achar esquisita, respeite também. Até eu fui obrigada a me respeitar.

Escrever é uma maldição. (LISPECTOR, 1999, pág. 74)1

De modo geral, pode-se afirmar que a humildade expressa pela escritora ao pedir desculpas por estar errando tanto na máquina é o seu modo de dizer ao linotipista que, se ele considera que gramaticalmente ela escreve errado e que sua pontuação é falha, tudo isso faz parte de seu processo de escritura e até mesmo ela teve que aprender a respeitar a si, já que escrever é bem mais que uma escolha, é uma maldição. Ao afirmar que a pontuação é a respiração da frase, ela assume a singularidade de suas frases que nem sempre obedecem aos padrões da linguagem convencional e nem mesmo as regras da gramática normativa, uma vez que a escrita clariciana vai se destacar principalmente pelo seu modo insólito de representar o real. Como afirma Maria Helena Falcão Vasconcellos:

A escrita-pensamento de Clarice é uma perseguição incansável de dizer o real, de se aproximar do real, de lhe captar o "quid" inapreensível. Clarice não pretende dizer extensivamente o real, ela o diz em intensidade, num esforço desesperado de dizer o indizível.

${ }^{1}$ Consideramos os textos de A descoberta do mundo (1999) e Cartas perto do coração (2001) mais adequados para demonstrarmos a relação da autora com sua biografia e sua escritura. 
A escrita de Clarice persegue o sussurro dos interstícios para dar-lhe língua. É pela escrita que Clarice se aproxima da estranheza inóspita do mundo e faz dessa aproximação um abrigo de palavras, um ensaio de sentido. (VASCONCELLOS, 2007, p.128-130)

É essa autonomia da linguagem que possibilita a percepção do texto como uma realidade virtual, livre das convenções do mundo, com uma respiração própria. Conforme nos alerta Heidegger (2008) quando diz que "a arte não é mais do que uma palavra a que nada de real já corresponde" (p. 11), fazendo-nos captar "o caráter coisal da obra de arte" (p. 13), pois para o filósofo:

A obra dá publicamente a conhecer outra coisa, revela-nos outra coisa; ela é alegoria. À coisa fabricada reúne-se ainda, na obra de arte, algo de outro. Reunir-se diz em grego $\sigma u \mu \beta \alpha ́ \lambda \lambda \lambda \varepsilon v$. A obra é símbolo. Alegoria e símbolo fornecem o enquadramento em cuja perspectiva se move desde há muito a caracterização da obra de arte. Só essa unidade na obra, que revela um outro, essa unidade que se reúne com algo de outro, é que é o elemento coisal na obra de arte. (HEIDEGGER, 2008, p. 13)

É esse elemento coisal que a obra clariciana apreende, exprime, manifesta, tendo em vista que ele não é apenas o princípio que a escritora procura seguir para redigir seus textos, ele é a própria essência da escritura de Clarice.

Desse modo, é flagrante captar no texto lispectoriano um conjunto de caracteres pessoais que possibilita aos leitores distinguí-lo dos demais registros e percebê-lo como uma unidade. Isso se dá, principalmente, pelo modo como a autora articula o outro em sua narrativa, num incessante desdobramento de si mesma.

Sobre o ato de escrever, Lispector complementa em outra crônica:

\section{ESCREVER}

Eu disse uma vez que escrever era uma maldição. Não me lembro porque exatamente eu o disse, e com sinceridade. Hoje repito: é uma maldição, mas uma maldição que salva.

Não estou me referindo muito a escrever para jornal. Mas escrever aquilo que eventualmente pode se transformar num conto ou num romance. É uma maldição porque obriga e arrasta como um vício penoso do qual é quase impossível se livrar, pois nada o substitui. E é uma salvação.

Salva a alma presa, salva a pessoa que se sente inútil, salva o dia que se vive e que nunca se entende a menos que se escreva. Escrever é procurar entender, é procurar reproduzir o irreproduzível, é sentir até o último fim o sentimento que permaneceria apenas vago e sufocador. Escrever é também abençoar uma vida que não foi abençoada. 
Que pena que só sei escrever quando espontaneamente a "coisa" vem. Fico assim a mercê do tempo. E, entre um verdadeiro escrever e outro, podem-se passar anos.

Lembro-me agora com saudade da dor de escrever livros. (LISPECTOR, 1999, p. 134)

O que primeiro chama a atenção nesse texto é o fato de escrever ser considerado algo maldito, mas que salva. Mas por que escrever seria uma maldição? Talvez pela impossibilidade de fuga a que o escritor está submetido, é como se escrever fosse para ele um destino predeterminado. Outro ponto é o certo distanciamento que a escrita jornalística toma dessa salvação, enquanto que o romance e o conto parecem intimamente vinculados a ela. $\mathrm{O}$ que poderia justificar essa afirmação? Certamente o fato de a escrita jornalística manter uma relação direta com a descrição da realidade, enquanto que a escrita literária pode simplesmente ficcionalizar o real e fazer uso das potencialidades imaginativas do autor e do leitor. Por isso é que a escritura que abençoa aos que não foram abençoados acontece espontaneamente quando a "coisa" vem - mas que "coisa"? Seria a inspiração? - e deixa o escritor a mercê de algo e sem poder controlar o tempo de sua escrita. Sobre a inspiração Blanchot (1987) afirma: "Para escrever, é preciso que já se escreva. Nessa contrariedade se situam também a essência da escrita, a dificuldade da experiência e o salto da inspiração". E acrescenta: "O salto é a forma ou o movimento da inspiração. Essa forma ou esse movimento não faz apenas da inspiração o que se pode justificar, mas reencontra-se em sua principal característica: nessa inspiração que, ao mesmo tempo e sob mesma relação, é falta de inspiração, força criadora e aridez intimamente confundidas” (pág. 177). Por fim, vale destacar a impossibilidade de precisar um tempo para a realização da escritura e os intervalos que existirão entre a produção de uma obra e outra, contudo é preciso ter em mente que "todo texto é escrito eternamente aqui e agora" (BARTHES, 2004).

A escritura ficcionalizada dos contos e dos romances, a que se pode chamar de escrita literária, é considerada por Clarice a maldição, mas, ao mesmo tempo, é ela quem salva e que ultrapassa os limites entre o real e o irreal. É através dela que o inexprimível poderá, talvez, ser contemplado e diante da qual a escritora se sente desnorteada, mas é nessa escritura que deposita suas esperanças de expressão:

\section{AINDA SEM RESPOSTA}

Não sei mais escrever, perdi o jeito. Mas já vi muita coisa no mundo. Uma delas, e não das menos dolorosas, é ter visto bocas se abrirem para dizer ou talvez apenas balbuciar, e simplesmente não conseguirem. Então eu quereria 
às vezes dizer o que elas não puderam falar. Não sei mais escrever, porém o fato literário tornou-se aos poucos tão desimportante para mim que não saber escrever talvez seja exatamente o que me salvará da literatura.

O que é que se tornou tão impotante para mim? No entanto, o que quer que seja, é através de literatura que poderá talvez se manifestar. (LISPECTOR, 1999, p. 112)

O que fica em destaque aqui é a relação do escritor com sua escritura. Uma relação construída às avessas e, talvez, exatamente por isso tão peculiar e tão sofrida. (Des)aprender a escrever depois de ter exprimido a si mesmo faz parte do árduo processo de nascimento, morte e renascimento a que o autor se submete a cada término e a cada nova tentativa de escrever. Em entrevista à TV Cultura, no dia $1^{\circ}$ de fevereiro de 1977, Clarice, ao ser indagada sobre seu livro A hora da estrela, mostra ter consciência das etapas a que está submetida a sua condição de escritora quando diz ao entrevistador Júlio Lerner: "Bem, agora eu morri... Mas vamos ver se eu renasço de novo... Por enquanto eu estou morta... Estou falando do meu túmulo" (Apud GOTLIB, 2009, p. 443).

Contudo, é preciso lembrar que o autor, ou melhor, a função autor, como destaca Michel Foucault em ¿Qué es un autor?, vai além da própria relação do autor com seu texto, apresentando caráter multifacetado e complexo e atinge o social, conforme destaca Foucault:

(...) la función-autor está ligada al sistema jurídico e institucional que ciñe, determina, articula el universo de los discursos; no se ejerce uniformemente y de la misma manera en todos los discursos, en todas las épocas y en todas las formas de civilización; no es definida por la atribuición espontánea de un discurso a su productor, sino por una serie de operaciones específicas y complejas; no remite pura y simplemente a un individuo real, ella puede dar lugar simultaneamente a varios egos, a varias posiciones-sujetos que diferentes clases de individuos pueden llegar a ocupar. (FOUCAULT, 1998, p. 52)

Refletir acerca das diversas possibilidades que a função autor pode assumir socialmente, é bem mais que ater-se a questão 'O que é um autor?' pura e simplesmente dita. Afinal, o autor é aquele que escreve, mas não é ele a peça fundamental e sim o que ele escreve, como escreve e quando escreve. Afinal, é a partir de sua escrita que ele poderá permanecer historicamente.

Interessante perceber que dessa aproximação da escrita com o que comumente designamos literatura, Clarice se sente num entre-lugar, pois quanto à literatura ela desabafa: 


\title{
DE UMA CONFERÊNCIA NO TEXAS
}

(...)Apesar de ocupada com escrever desde que me conheço, infelizmente faltou-me também encarar a literatura de fora para dentro, isto é, como uma abstração. Literatura para mim é o modo como os outros chamam o que nós fazemos. E pensar agora em termos de literatura está sendo para mim uma experiência nova, não sei ainda se proveitosa. De início pareceu-me desagradável: seria por assim dizer, com uma pessoa referir-se a si própria como sendo Antônio ou Maria. Depois a experiência tornou-se menos má: chamar-se a si mesmo pelo nome que os outros nos dão, soa como uma convocação de alistamento. Do momento em que eu mesma me chamei, senti-me com algum encanto alistada. Alistada, sim, mas bastante confusa. (...) (LISPECTOR, 1999, pág. 118)

O que mais chama a atenção nessa declaração é a íntima relação que Clarice possui com a literatura enquanto exercício de escritura, embora o mesmo não aconteça quando fala em literatura como atividade de crítica literária. Aliás, é digno de nota que a escritora Clarice Lispector se preocupava muito com o que os críticos literários comentavam a respeito de seus livros. Ela fazia questão de acompanhar, mesmo à distância, os comentários que saíam sobre os seus livros publicados no Brasil. Não se sentia bem com as críticas severas que alguns dispendiam, mas também ficava angustiada quando a crítica não se pronunciava a respeito de algum de seus livros. Em carta a Fernando Sabino, confessa:

\begin{abstract}
Encontrei cartas de casa e vários recortes de jornal, artigos de Reinaldo Moura, nota de Lazinha Luiz Carlos de Calda Brito..., várias notinhas, referências a você e a mim em Sérgio Milliet, e em vários. E nota de Álvaro Lins dizendo que meus dois romances são mutilados e incompletos, que Virginia parece com Joana, que os personagens não têm realidade, que muita gente toma a nebulosidade de Claricinha como sendo a própria realidade essencial do romance, que eu brilho sempre, brilho até demais, excessiva exuberância... Com cansaço de Paris, no meio de caixotes, femininamente e gripada chorei de desânimo e cansaço. Só quem diz a verdade é quem não gosta da gente ou é indiferente. Tudo que ele diz é verdade. Não se pode fazer arte só porque se tem um temperamento infeliz e doidinho. Um desânimo profundo. Pensei que só não deixava de escrever porque trabalhar é a minha verdadeira moralidade. (LISPECTOR\&SABINO, 2001, p. 21)
\end{abstract}

A partir desse fragmento poderíamos considerar que Clarice é refém da crítica, porém, como é sabido, ela não se rende aos comentários desanimadores e muito menos muda o seu modo de escrever. Pelo contrário, ela vê a sua escrita como um trabalho que dignifica e dá moralidade. Em resposta a esta carta, o amigo Fernando Sabino afirma:

Então é preciso descobrir antes o que é o nosso livro (...) Só o que vai ser se descobrirmos para o que vaij servir ou que utilidade terá, avançamos demais e caímos na propaganda, na arte social ou na literatice (...) Digo apenas que não concordo com você quando você diz que faz arte porque 
"tem um temperamento infeliz e doidinho". Tenho uma grande, uma enorme esperança em você e já te disse que você avançou na frente de todos nós, passou pela janela, na frente de todos. Apenas desejo intensamente que você não avance demais para não cair do outro lado. Tem de ser equilibrista até o final. (LISPECTOR\&SABINO, 2001, p. 28)

Interessante perceber como dois renomados escritores da atualidade expressam suas impressões e sensações a respeito do ato de escrever e de como se portam diante da crítica de sua época. São enriquecedoras também as informações que trocam sobre o processo de feitura de seus livros, as sugestões que fazem um ao outro e os desabafos angustiados que fazem quando estão esperando o livro que está por vir. A riqueza da diversidade dos assuntos tratados nessas cartas, o modo como ambos expõem seus pensamentos e angústias acerca do fazer poético, mostrando o escritor como uma pessoa comum, do cotidiano, mas que tem um olhar diferenciado sobre as coisas do mundo, reafirma a importância do arquivo dos escritores.

Para finalizar, será tratado um processo bastante explorado por Clarice que é a utilização da entrelinha para dizer algo mais, para manifestar o pensamento que a linguagem sozinha não consegue expressar. Afinal, o que é a Literatura senão esse eterno vir a ser, essa busca constante de transpor os limites da linguagem, essa coisa variável, inapreensível e inconstante? O que é a Literatura senão a junção das diversas possibilidades de representação? Uma representação que será sempre uma tentativa, um experimento, um desejo de expressar o real, mas que por mais próximo que consiga chegar a ele, nunca será o real em sua essência. Acredita-se que seja essa uma das grandes maestrias da escritura clariciana, o preenchimento da ideia manifesta nas entrelinhas.

\section{ESCREVER AS ENTRELINHAS}

Então escrever é o modo de quem tem a palavra como isca: a palavra pescando o que não é palavra. Quando essa não-palavra - a entrelinha morde a isca, alguma coisa se escreveu. Uma vez que se pescou a entrelinha, poder-se-ia com alívio jogar a palavra fora. Mas aí cessa a analogia: a nãopalavra, ao morder a isca, incorporou-a. O que salva então é descrever distraidamente. (LISPECTOR, 1999, p. 385)

Nessa pequena crônica é possível perceber através da analogia entre o ato de escrever e o de pescar, no gracejo entre a palavra e a não-palavra que a escrita lispectoriana é, sobretudo, poética, pois em seu texto há o que Manoni denomina de "realidade poética", ou seja, a realidade que é “despercebida pelo homem prosaico, misteriosa, mística. Mas 
sobretudo que fala" (MANONI, 1973, p. 223). É baseando-se nisso que o estudioso considera que o poeta chega muito perto "da fonte inconsciente da palavra" a qual também se pode afirmar alcançou Clarice.

Instigante conceber esse caráter poético da prosa clariciana, tão próxima a essa fonte inconsciente, lembrando que "a poesia constitui ao mesmo tempo o sonhador e seu mundo" (BACHELARD, 2006, p. 16) tornando o leitor "um sonhador de palavras, um sonhador de palavras escritas" (p. 17), pois na obra de Clarice "as palavras assumem então outros significados, como se tivessem o direito de ser jovens” (Id., Ib., p. 17). Tudo isso porque são "palavras cósmicas, palavras que dão o ser do homem ao ser das coisas". E é exatamente isso que ocorre em Clarice, através de uma linguagem 'distorcida', incomum, mas eivada de significados e significantes capazes de fazer com que o ovo e a galinha, por exemplo, ganhem dimensões extremamente filosóficas. Sobre a importância das entrelinhas na prosa clariciana, Leyla Perrone-Moisés aponta:

\begin{abstract}
Enquanto escritora, Clarice não acreditava nem um pouco na capacidade da linguagem para dizer 'a coisa', para exprimir o ser, para coincidir com o real. O que ela queria - ou melhor, devia, já que escrever era para ela missão e condenação - era 'pescar as entrelinhas'. O que ela buscava não era da ordem da representação ou da expressão. Ela operava emergências de real na linguagem, urgências de verdade. Resta ao leitor receber suas mensagens em branco, e ouvir o que de essencial se diz em seus silêncios. (PERRONEMOISÉS,1990,177)
\end{abstract}

Ante o exposto, pode-se afirmar que é portando-se como refém, mas agindo como mestre que Clarice atinge o âmago de sua escritura e consegue exprimir com tanta sensibilidade artística a condição subjetiva do homem ${ }^{2}$. É através da respiração de sua frase e da exposição de seus pensamentos mais íntimos que a autora expõe o outro bem como a si mesma, ultrapassando os escritores de seu tempo e explicitando a importância das entrelinhas na formação de seu texto e de sua vida.

\title{
REFERÊNCIAS:
}

BACHELARD, Gaston. A poética do devaneio. Trad. Antônio de Pádua Danesi. 2. ed. São Paulo: Martins Fontes, 2006.

${ }^{2} \mathrm{O}$ vocábulo homem aqui está sendo utilizado no seu sentido genérico, portanto, designa tanto o masculino quanto o feminino. 
BARTHES, Roland. A morte do autor. In: $O$ rumor da língua. Trad. Mario Laranjeira. São Paulo: Martins Fontes, 2004.

BLANCHOT, Maurice. A inspiração. In: $O$ espaço literário. Trad. Cabral. Rio de Janeiro: Rocco, 1987. p.163-176.

CANDIDO, Antonio. A educação pela noite. 5. ed. revista pelo autor. Rio de Janeiro: Ouro sobre Azul, 2006.

CANDIDO, Antonio. Formação da literatura brasileira. Belo Horizonte: Ed. Itatiaia,1981.

FOUCAULT, Michel. ¿Qué es un autor?. Trad. Silvio Martoni. In: Litoral. Número 25/26. Córdoba: Edelp, 1998.

GOTLIB, Nádia Battella. Entrevista de Clarice Lispector à TV Cultura, $1^{\circ}$ de fevereiro de 1977. In: Clarice: Fotobiografia. 2. ed. São Paulo: Editora da Universidade de São Paulo EDUSP, 2009.

HEIDEGGER, Martin. A Origem da Obra de Arte. Trad. Maria da Conceição da Costa. Lisboa: Edições 70, 2008.

LISPECTOR, Clarice. A descoberta do mundo. Rio de Janeiro: Rocco, 1999.

. Laços de família. Rio de Janeiro: Rocco, 1998.

. A Bela e a Fera. Rio de Janeiro: Rocco, 1999b.

. A hora da estrela. Rio de Janeiro: Rocco, 2006.

. Correspondências. Org. Teresa Montero. Rio de Janeiro: Rocco, 2002.

; SABINO, Fernando. Cartas perto do Coração. Rio de Janeiro: Record, 2001.

MANONI, O. Chaves para o imaginário. Trad. Lígia Maria Pondé Vassalo. Petrópolis: Vozes, 1973.

PERRONE-MOISÉS, Leila. Flores da escrivaninha. Companhia das Letras: São Paulo, 1990. PONTIERI, Regina Lúcia. Clarice Lispector uma poética do olhar. Ateliê editorial: São Paulo, 1999.

VASCONCELLOS, Maria Helena Falcão. A escrita de Clarice Lispector gagueja o indizível. In: Cerrados: revista do Programa de Pós-Graduação em Literatura. Brasília, DF: Universidade de Brasília, 2007. Tema especial: Literatura e presença: Clarice Lispector. Vol. 16, N. 24 (semestral).

RECEBIDO EM: 07 de maio de 2012

APROVADO EM: 08 de junho de 2012 